\title{
The Impact of Supervisor-Subordinate Incongruence in Power Distance Orientation on Subordinate Job Strain and Subsequent Job Performance
}

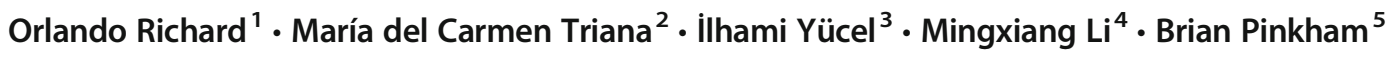 \\ Accepted: 19 February 2021 / Published online: 5 April 2021 \\ (C) The Author(s), under exclusive licence to Springer Science+Business Media, LLC, part of Springer Nature 2021
}

\begin{abstract}
Employee strain is estimated to cost American companies as much as $\$ 500$ billion in lost productivity annually, and a leading cause of workforce stress is disagreements with other people (Cook, 2017; Mental Health America, 2017). In this study, we investigate supervisor-subordinate value incongruence as a cause of employee strain. Specifically, this study examines the effect of supervisor-subordinate power distance orientation incongruence on the subordinate's job strain which, in turn, influences the subordinate's job performance. Using a sample of 172 supervisor-subordinate dyads, we find that incongruence on power distance orientation increases subordinate job strain. Supervisor-subordinate incongruence resulted in more job strain which, in turn, resulted in lower job performance. Results reveal that the alignment of subordinates' cultural values with those of their supervisors may mitigate negative experiences and facilitate more positive work outcomes.
\end{abstract}

Keywords Incongruence $\cdot$ Power distance $\cdot$ Strain $\cdot$ Job performance $\cdot$ Supervisor-subordinate dyads $\cdot$ Role theory $\cdot$ Transactional model

"Everyone who has ever held a job has, at some point, felt the pressure of work-related stress."-American Psychological Association

Orlando Richard and María del Carmen Triana share equal authorship.

María del Carmen Triana

Maria.triana@vanderbilt.edu

Orlando Richard

orichard@isenberg.umass.edu

İlhami Yücel

iyucel@erzincan.edu.tr

Mingxiang Li

lim@fau.edu

Brian Pinkham

pinkham@rsm.nl

1 University of Massachusetts Amherst, Amherst, MA, USA

2 Vanderbilt University, Nashville, TN, USA

3 Erzincan Binali Yıldırım University, Erzincan, Turkey

4 Florida Atlantic University, Boca Ranton, FL, USA

5 RSM, Erasmus University, Rotterdam, Netherlands
Employee stressors and their resulting strain are among the leading causes of workplace inefficiency, illness, and absence. According to the American Psychological Association (APA), $65 \%$ of Americans cite work as a key source of stress (APA, 2018). The American Institute of Stress (2018) reports that the two leading workplace stressors are workload followed by people issues (i.e., disagreements with other people). Strain, which is defined by the APA (2020) as "the state of a system on which excessive demands are made" takes a heavy human toll on employees as well as a financial toll on organizations. Workplace stress has been estimated to cost American companies as much as $\$ 500$ billion annually, and "as many as 10 percent of U.S. employees who miss work due to on-the-job stress may be absent from work for 21 days or more a month" (Cook, 2017; Mental Health America, 2017). The Centers for Disease Control (CDC) corroborates the high impact stress has on employees. The CDC states that "work-related stress is the leading workplace health problem and a major occupational health risk, ranking above physical inactivity and obesity" (Centers for Disease Control, 2016). According to an article by Pfeffer (2020) on solving the workplace health crisis, the CDC estimates that approximately $90 \%$ of the $\$ 3.3$ trillion the USA spends on health care every year funds chronic diseases and mental health (CDC, 2019). "In 2005, 
Starbucks paid more for health benefits than it did for coffee, and recently the three major U.S. automakers spent more for healthcare than they did for steel" (Pfeffer, 2020).

The present study investigates the aspect of employee strain triggered by "people issues," and specifically, strain driven by having incompatible values with one's supervisor. We focus on the supervisor-subordinate relationship, because experiencing tension with one's supervisor could be a key stressor for employees, as supervisors have legitimate authority over employees with respect to performance appraisal, compensation, promotion, assignments, and termination. Moreover, in this era of increased cultural diversity, it is more likely than ever that subordinates and supervisors will have different cultural values concerning the nature of work and role expectations (Jun \& Gentry, 2005; Taras et al., 2012). This creates potential tension and job strain for employees.

We propose that - in addition to possessing the necessary task knowledge, ability, and skills for the job-making job assignments and retaining workers who have similar value orientations to their supervisor is critical for employees to be most effective in their jobs (Clarke \& Mahadi, 2017; Erez, 2010; Posner, 2010). Although some research indicates that value congruence is primarily relevant for values associated with performance evaluations (Seggewiss et al., 2019), when value congruence between a supervisor and subordinate is high, subordinates are more likely to accept their supervisor because they perceive him or her to have similar beliefs to them (Zhang et al., 2012). Yet, research on congruence (or incongruence) in cultural value orientations of supervisorsubordinate dyads and subsequent outcomes (such as wellbeing and performance) is limited.

For example, research on cultural values in cross-cultural studies has focused on comparing and contrasting societal level cultural values and documenting differences in behavior that arise from those value differences. As this comparative literature mostly focuses on finding cultural differences on average, across countries at the societal level, much less attention has been paid to identifying what kinds of intercultural challenges subordinates and supervisors face at the individual level, and how they could manage such challenges (Imai \& Gelfand, 2010). Furthermore, the vast majority of studies on cultural values have focused on individualism/collectivism (IC). Indeed, in their annual review of cross-cultural organizational behavior, Gelfand, Erez, and Aycan (2007, p. 496) aptly lamented that, "future research sorely needs to move beyond the IC obsession to explore other constructs....". Thus, other than individualism/collectivism, the relationship of individual-level cultural values with work outcomes is not well understood.

Accordingly, the purpose of this research is to examine the individual-level cultural value orientation (in)congruence between a subordinate and a supervisor and its consequences at work. We focus on the value of power distance orientation because it represents a major individual cultural value shown to distinguish individuals across and within cultures (Kirkman et al., 2009). Power distance orientation refers to acceptance of hierarchy and status differences, as well as the expectations of at least two key actors - those with power over individuals (e.g., supervisors) and those who are lower in the power structure (e.g., subordinates) (Clugston et al., 2000; Kirkman et al., 2006). Power distance orientation is highly relevant to the work context, and (in)congruence between supervisorsubordinate dyads on this value has important consequences in organizations (Farh et al., 2007; Kirkman et al., 2009).

Our main proposition is that power distance orientation incongruence between supervisors and subordinates leads to subordinate job strain, and ultimately, lower job performance from the subordinate. By integrating role theory (Katz \& Kahn, 1966) and the transactional model of stress, appraisal, and coping (Lazarus, 1966; Lazarus \& Folkman, 1984), we suggest that strain is a potential mediator of the relationships between power distance orientation value incongruence and job performance. In doing so, the present study builds upon previous strain research (Jackson, 1983; Lang et al., 2007).

Role theory describes that people in organizations play different roles depending upon their formal position and its associated expectations. Exchanges between employees in the form of role episodes are influenced by both formal job titles and individual differences of each actor involved. This explains how stressors may arise from role episodes where the two parties have incongruent cultural value orientations. Although role theory differentiates between prescribed roles (e.g., task performance) and discretionary roles (e.g., contextual performance such as citizenship behavior; Motowidlo \& Van Scotter, 1994), this paper focuses primarily on the former. Moreover, we use the transactional model of stress (Lazarus \& Folkman, 1984) together with role theory to extend the culture literature and understand the strain that can result from supervisor-subordinate value incongruence. The transactional model describes how people conduct an appraisal of the stressor to determine how to respond (Lazarus \& Folkman, 1984). By integrating the supervisor-subordinate value (in)congruence literature with culture research, we expand the culture literature and move beyond one-sided perspectives where the power distance orientation of either the subordinate or the supervisor is considered (Farh et al., 2007; Kirkman et al., 2009).

Practically, by simultaneously considering dyadic supervisor-subordinate value orientation (in)congruence rather than focusing on the value orientation of only the subordinate (e.g., Loi et al., 2012), we provide a more detailed and comprehensive analysis of supervisor-subordinate relationships. This is increasingly important in culturally diverse organizations where supervisors and subordinates can have divergent values on a number of dimensions, yet need to work together so employees' sense of well-being is fulfilled and 
they can be productive. We test our theoretical model by conducting a field study using a sample of 172 supervisorsubordinate dyads, and we offer implications for future research and practice.

\section{Theory Development and Hypotheses}

Role theory (Katz \& Kahn, 1966) provides a theoretical framework to understand why incongruence in cultural value orientation is important in supervisor-subordinate dyads. Role theory is based on the idea that, in every organization, people participate in a series of role episodes, or interactions with others. The role that an individual takes on depends upon the expectations of their position (e.g., formal authority, job responsibilities), as well as social norms in the organization, and the personalities and values of each participant in a role episode. Because both parties in a role episode have expectations about how things should unfold based on their understanding and their value-driven perceptions, having incongruent value orientations from the other person can shape the outcomes of the role episode.

Person-environment fit (P-E fit) theory, which is derived from role theory (French et al., 1982), can also help explain the dynamics between a supervisor and subordinate who have incongruent values. For example, person-person fit refers to the fit between an employee's cultural preferences and the preferences of others including their supervisor which would drive person-supervisor fit (Edwards \& Shipp, 2007). A person's characteristics can include their values and work goals, while environmental characteristics can include company culture, role demands, rewards, and the characteristics of others in the work environment, including the supervisor (French et al., 1982). We now turn our attention to incongruence on power distance orientation, an important cultural value.

\section{Power Distance Orientation}

Hofstede (2001) defines power distance as the degree of inequality among people which a culture considers normal, ranging from relatively equal (low power distance) to extremely unequal (high power distance) (see also, Singelis et al., 1995). At an individual level, these differences are manifested in an individual's power distance orientation, indicating "the extent to which an individual accepts the unequal distribution of power in institutions and organizations" (Clugston et al., 2000, p. 9). We adopt Kirkman et al.' (2009) term power distance orientation, or individually held values on power distance.

High Power Distance Orientation Subordinates Individuals with high power distance orientation will exhibit sensitivity to the chain of command and organizational structure (Lee \&
Antonakis, 2014; Tyler et al., 2000). High power distance orientation subordinates prefer to have less communication with and maintain greater social distance from managers (Farh et al., 2007; Kirkman et al., 2009). They accept that subordinates have inferior status to the supervisor (Tyler et al., 2000), have little (or no) voice in organizational decision-making (Brockner et al., 2001), and are generally afraid and unwilling to express disagreement with their superiors (Gelfand et al., 2004). High power distance orientation subordinates also prefer to work for supervisors who make decisions (and take responsibility) and clearly outline duties and tasks for subordinates (Erez, 1994; Javidan et al., 2006; Triandis et al., 1994). Not only do high power distance subordinates expect explicit direction but they also expect solutions to come from their supervisors (Javidan et al., 2006).

High Power Distance Orientation Supervisors Supervisors with high power distance orientation will use autocratic behavior with limited one-way communication, will not tolerate disagreement, and will view criticism from subordinates as insubordination (Brockner et al., 2001). Similarly, supervisors will not consult subordinates when making decisions and expect subordinates to simply follow or obey their decisions (Cole et al., 2013). Status tends to attach visibly to supervisor positions, as both the supervisors and the subordinates consider each other as existentially unequal (Hofstede, 2001). High power distance supervisors will not justify actions to members lower in the hierarchy (Carl et al., 2004).

Low Power Distance Orientation Subordinates In contrast, individuals with low power distance orientation are likely to expect feedback, freely give opinions and make observations, and value autonomy over structure (Kirkman et al., 2009; Loi et al., 2012). The subordinate may challenge the task set by a supervisor with the intent to improve upon the work outcome, may expect more task autonomy, and may openly offer comments and opinions (Dorfman \& Howell, 1988). Similarly, these individuals prefer egalitarian processes and are less likely to submit to authority (Kirkman et al., 2009). Low power distance subordinates will prefer task autonomy and a participative supervisor and are likely to have a personalized relationship with their supervisor (Bochner \& Hesketh, 1994).

Low Power Distance Orientation Supervisors Similar to the low power distance orientation subordinates, low power distance orientation supervisors may include the input of work associates (superior, peer, and subordinate) and may pursue activities with subordinates outside the context of the workplace (Kirkman et al., 2009). They are more likely to consult team members when making decisions, engage in discussion and elicit buy-in, and allow the subordinate to openly disagree with them in public. Low power distance orientation supervisors often view functional disagreements as appropriate and 
even desirable (Cole et al., 2013). Overall, low power distance orientation supervisors are more likely to view subordinates and superiors as equal, resulting in increased exchange for decision-making, subordinate autonomy, and delegation of important tasks (Dorfman \& Howell, 1988).

\section{Supervisor-Subordinate Power Distance Orientation (In)congruence and Strain}

Role theory (Katz \& Kahn, 1966) explains why misunderstandings can result in strain, described as "a sense of time pressure, anxiety, and worry that is associated with job tasks" (Hunter \& Thatcher, 2007, p. 945) during role episodes when the two actors have incongruent power distance orientations. Because role senders and role receivers involved in a role episode filter the other person's message using their own values and then act based upon that interpretation, incongruence on power distance orientation could lead to mismatches between the meaning behind messages sent and received. Incongruence can also result in differences of opinion on how to respond. These mismatches between role senders and receivers can have negative consequences on subordinate well-being (Edwards et al., 1998; Edwards et al., 2006; Kristof-Brown et al., 2005; Lee \& Antonakis, 2014; Rahimnia \& Sharifirad, 2015) such as strain (Caplan, 1987; Edwards \& Van Harrison, 1993).

In our setting, value incongruence is rooted in a mismatch between the values of the supervisor and subordinate and ultimately leads to individual strain (Beehr \& Bhagat, 1985; Beehr et al., 2000). Lovelace and Rosen (1996) found lower levels of job strain for individuals who perceived a better fit between themselves and their organization on several dimensions (e.g., values, ethics, goals and objectives, skills, etc.). Saks and Ashforth (1997) found that individuals who perceived better fit with their job experienced less misfit, which reduced job strain (Edwards \& Van Harrison, 1993). Similarly, individuals perceive less misfit (a critical component of strain (Beehr et al., 2000)) if they are matched with supervisors in terms of their style of supervision and the situation (Chemers et al., 1985).

The supervisor-subordinate relationship shapes an employee's experience (Skiba \& Wildman, 2019). When individuals and their supervisors share similar values (congruence), individuals may experience greater feelings of affect, respect, and trust for their supervisors, leading to increased commitment, decreased role stressors, decreased job anxiety, and reduced intention to leave (Adkins \& Russell, 1997; Krishnan, 2002; Meglino et al., 1989; Turban \& Jones, 1988; Van Vianen, 2000; Wexley et al., 1980). Value orientation congruence promotes communication because the actors involved in the dialogue have a common way to interpret and describe events (Edwards \& Cable, 2009; Erdogan et al., 2004). When a supervisor-subordinate dyad shares a common way to think about things, their chances of having disagreements that could invoke a stressful situation should be reduced. In contrast, supervisor-subordinate dyads with dissimilar values are more likely to experience negative interpersonal interactions with each other as a result of not being able to predict each other's behaviors and experience high role ambiguity that may lead to strain (Kristof-Brown et al., 2005; Jackson, 1983; Ostroff et al., 2005). Furthermore, employees who experience low value congruence are more likely to report cognitive dissonance (Cable \& DeRue, 2002), which occurs when employees are required to behave in ways that are not consistent with their beliefs and values (Liao et al., 2004; Zhang et al., 2012).

When there is power distance orientation incongruence, the subordinate will have expectations that diverge from the expectations of the supervisor. For instance, a subordinate with high power distance orientation expects decision-making to occur at the supervisory level (Kirkman et al., 2009). In contrast, a supervisor with low power distance orientation believes that the subordinate's input for decision-making is important to the process and may misinterpret respect for authority as a sign of shirking. Similarly, a supervisor with high power distance orientation may view a subordinate with low power distance orientation as inappropriately interfering if the subordinate offers their opinion or attempts to participate in decision-making (Kirkman et al., 2009). Role theory would predict that such disconnects between supervisors and subordinates can lead to subordinate strain because their mutual expectations about how role episodes should play out are not being confirmed. Based on theory (Katz \& Kahn, 1966) and related empirical evidence (e.g., Rahimnia \& Sharifirad, 2015), we make the following prediction.

- Hypothesis 1: the more incongruent a subordinate's and his or her supervisor's level of power distance orientation is, the higher the subordinate's strain.

Although role theory (Katz \& Kahn, 1966) clarifies why (in)congruence on power distance orientation can result in (more) fewer stressors between supervisors and subordinates, it does not explain the coping mechanisms that employees may use as a result of incongruent situations where stressors occur. To explain the coping mechanisms employees may deploy to combat stressors, we turn to the transactional model of stress, appraisal, and coping developed by Lazarus and Folkman (1984).

\section{Job Strain as a Mediator of the Supervisor- Subordinate Incongruence Effect on Job Performance}

The transactional model (Lazarus, 1966; Lazarus \& Folkman, 1984) describes the process through which people assess and react to stressors. According to the model, individuals first go 
through a primary appraisal process to determine the nature of the threat. A threat may be seen as irrelevant, in which case, it is likely ignored. In addition, a threat may be seen as benign or positive, in which case, it could be beneficial. However, a stressful encounter is a threat which could be harmful. If a harmful threat is detected, then people engage in a secondary appraisal process to determine what can be done about the threat (Folkman \& Lazarus, 1985, 1990; Lazarus \& Folkman, 1984). According to Perrewé and Zellars (1999), the secondary appraisal process involves evaluating the resources one has at his/her disposal in order to cope with the problem. For example, an employee may decide to work harder, withdraw from the situation, do more positive thinking, or do a cognitive reappraisal to change one's point of view (Perrewé \& Zellars, 1999).

LePine et al. (2005) showed that stressors such as supervisor-subordinate incongruence will fall into one of two categories: challenge-oriented (workload, time, job scope) or hindrance-oriented (organizational politics, red tape, role ambiguity) stressors. We argue that supervisorsubordinate incongruence in power distance orientation most closely resembles a hindrance-oriented stressor because it is prone to creating individual strain such as "resource inadequacy" and "supervisor-related stress" (LePine et al., 2005, p. 767). Consequently, supervisor-subordinate incongruence in power distance orientation should increase strain and, ultimately, lead to lower job performance. People generally apply emotion-focused coping to situations which they feel they cannot change. If a subordinate simply does not share the same values as a supervisor, the subordinate may see this situation as somewhat unchangeable, or a hindrance stressor (Lazarus \& Folkman, 1984).

Although there are many antecedents to employee strain, we propose that value incongruence with one's supervisor is one of them. When there is congruence on power distance orientation between subordinates and supervisors, strain should be minimal, because similarity between subordinates and supervisor is likely to promote working toward a common goal, which may lead to more participation overall (Khatri, 2009). Khatri (2009) argued that, when the supervisorsubordinate dyad shares values, persons are more likely to maintain the status quo. This, in turn, will create common expectations between the subordinates and supervisors that will reduce strain and improve the subordinates' job performance (Farh et al., 2007). If supervisor-subordinate congruence leads to a more developed relationship between a subordinate and a supervisor, stress should be low, and employee job performance should be high because employees have their full mental energy available.

When there is incongruence of power distance orientation between subordinates and supervisors, differences should be more obvious, and tensions should rise between subordinates and supervisors. As a subordinate's job strain with their supervisor grows, we anticipate that the subordinate will reach both the primary and secondary appraisal stages of the stress process according to the transactional model (Lazarus \& Folkman, 1984). In the secondary appraisal of stress, the employee is trying to decide how to cope with a stressor which is taxing his/her personal resources (Lazarus \& Folkman, 1984; Perrewé \& Zellars, 1999). At this level of stress, cognitive distractions may divert employees' attention from fully engaging in productive pursuits, because realizing that one has a low-quality relationship with one's supervisor is bothersome. This could thereby reduce job performance. Particularly when the problem arises from a deep-seated value difference between the supervisor and subordinate, the subordinate may opt to withdraw from the situation if it is seen as a lost cause rather than pouring more hard work or positive thinking into a situation that cannot be changed (Perrewé \& Zellars, 1999). In summary, we expect that supervisor-subordinate power distance orientation incongruence will indirectly decrease subordinate job performance. Furthermore, subordinate strain will mediate the relationship between supervisor-subordinate power distance orientation incongruence and subordinate job performance. The following hypothesis is proposed:

- Hypothesis 2: subordinate job strain mediates the negative relationship between supervisor-subordinate power distance orientation incongruence and subordinate job performance.

\section{Method}

\section{Sample}

Data were collected from experienced employees associated with a graduate program at a major US university and their direct supervisors at work. Surveys were first distributed to these individuals, and they were asked to invite their direct supervisors to fill out the supervisor survey. Since participants are from various firms, each supervisor provided only one survey. Collecting data from both the subordinate and his/ her direct supervisor helps increase the external validity of the current study (Rosenthal \& Rosnow, 2008) and minimize common method variance concerns.

Participation was voluntary and confidential. The supervisor survey was sealed and signed over the seal by the participating supervisor and either mailed, emailed, or faxed back to the researcher. For convenience, an online survey was designed and provided for employees whose supervisor preferred the online version, but all supervisors opted to return the paper copy. Supervisor contact information was requested voluntarily in the survey to allow random checks for true 
submissions, which increases the authenticity of the data collected. Individuals were awarded extra credit for both the employee and supervisor surveys. Each survey included a cover page explaining the purpose and procedures of the study and a questionnaire containing instructions, construct items, and scales. The employee survey included demographics as well as key measures such as strain and power distance orientation. The supervisor survey was collected one month later than the employee survey and included supervisor demographics, power distance orientation, and a rating of their subordinate's job performance. The employee survey and supervisor survey were later matched using an identification code generated by the student participant to ensure confidentiality (Tepper \& Taylor, 2003).

All working students, primarily in the private sector, who were invited to participate in the study for extra credit did so, for an initial response rate of $100 \%$. Moreover, $56 \%$ of them also obtained a complete supervisor survey. A total of 172 listwise comparison pairs of matched supervisor and subordinate surveys were collected. The final sample included employees from a broad cross-section of jobs, including manufacturing $(17.8 \%)$, wholesale $(3.5 \%)$, retail $(7.7 \%)$, service $(42.7 \%)$, healthcare $(6.9 \%)$, government and education $(12.9 \%)$, and other $(8.4 \%)$. The mean work experience for subordinates in their current job was 2.87 years while mean overall work experience was 7.26 years. Of the respondents, $61.8 \%$ were male, and the average age was 26 years (range of 18 to 59 years). In terms of race, $42.7 \%$ of the employees were from the White majority status racial subgroup. The remaining participants from racial minority status subgroups were Asian (46.1\%), Hispanic (6.2\%), Black (3.4\%), and other (1.7\%). All measures used a five-point Likert-type scale unless otherwise stated. Table 1 presents the summary statistics and correlations.

\section{Dependent Variables}

Strain (Subordinate-Reported) Strain was adopted from Hunter and Thatcher (2007). It consisted of six items on a five-point Likert scale with a Cronbach alpha of .86. A sample item is, "There are lots of times when my job drives me right up the wall."

Job Performance (Supervisor-Reported) Innovative job performance was collected from the supervisor, because the supervisor is charged with the appraisal of the subordinate's work. The measure was adopted from Farh et al. (1991) and consisted of three items measured on a five-point Likert scale with a Cronbach alpha of .82. A sample item is, "Your overall appraisal of the subordinate quality of work? In other words, are his/her work outcomes perfect, free of error, and of high accuracy?"

\section{Independent Variables}

Power Distance Orientation (Subordinate- and SupervisorReported) Individuals and their supervisors evaluated their own power distance orientation using the six-item Dorfman and Howell (1988) scale. For subordinates (supervisors), the Cronbach alpha was .74 (.75). A sample item is "managers should seldom ask for the opinions of employees."

\section{Control Variables}

We first controlled for dyad relationship conflict difference. Because research has shown that conflict differences between a subordinate and their supervisor impacts subordinate stress (Tillman et al., 2017), we collected relationship conflict with Jehn's (1995) four-item scale from both the subordinate and supervisor. We computed the mean of each and subtracted the difference such that higher positive (negative) values imply the subordinate (supervisor) perceived higher dyadic conflict than the supervisor (subordinate). A sample item is "My supervisor (subordinate) and I have tension in our relationship." We controlled for additional factors, including dyad tenure (Zhang et al., 2012) measured as the number of years the supervisor managed the subordinate (collected from the supervisor), because longer tenure may result in less strain. Furthermore, to account for supervisor human capital, we controlled for supervisor education (category levels) and supervisor work experience (number of years). Supervisor education category levels ranged from low to high: 8 th grade, high school, some college, college degree of 4 years, masters, and doctorate. We also controlled for both subordinate and supervisor genders ( $\operatorname{coded} 0=$ male, $1=$ female) to reflect gender differences in strain and any potential gender-based performance ratings. We controlled for subordinate age (10 categories where higher coding represents older age; (e.g., $1=18$ $24 ; 10=$ over 64 with exact categories $18-24,25-29,30-34$, $35-39,40-44,45-49,50-54,55-59,60-64$, over 64$)$. We also controlled for subordinate minority versus majority racial status (coded $0=$ other races, $1=$ white). To rule out industry effects, we included a service industry dummy variable (coded $0=$ other industries, $1=$ service industry).

\section{Results}

Because we collected several measures in the employee survey, we ran a confirmatory factor analysis (CFA) in LISREL (8.80) to establish the discriminant validity of the measures. A two-factor solution (power distance and strain) was a somewhat adequate fit for the data $\left(\chi^{2}=174.29, p<.01, \mathrm{df}=53\right.$, $\mathrm{CFI}=.88, \mathrm{IFI}=.89, \mathrm{RMSEA}=.09)(\mathrm{Hu} \&$ Bentler, 1999; Kline, 2005), and the modification indices indicated that two items on the strain scale had correlated errors, which is 


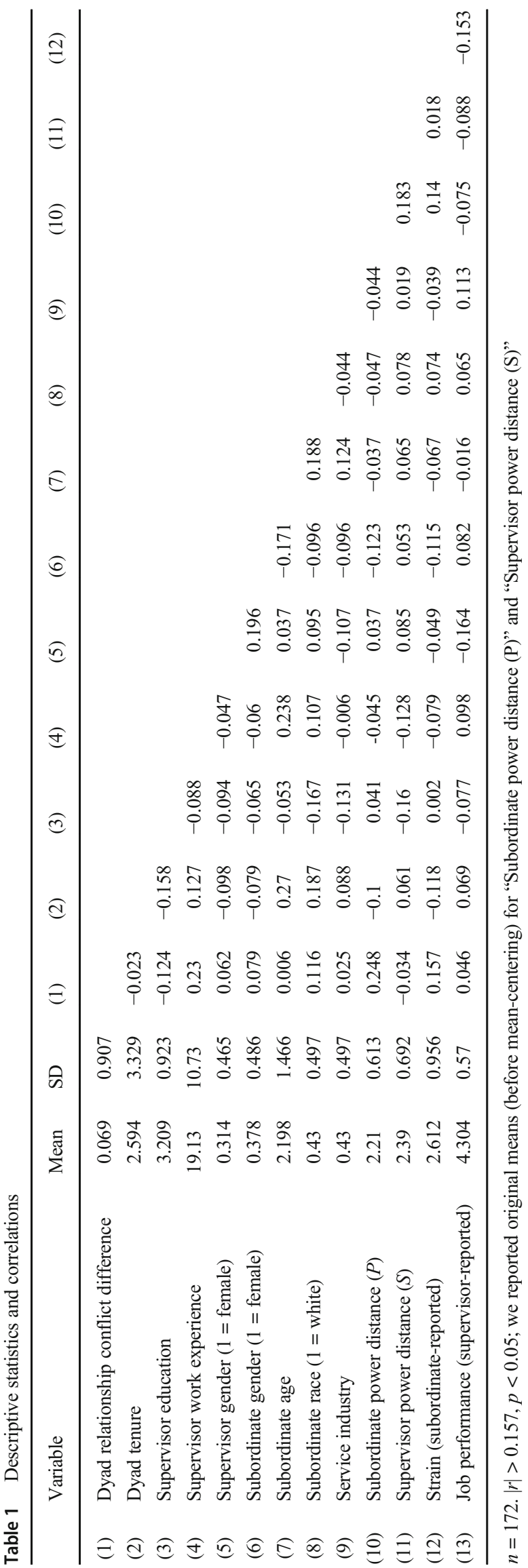

common in social sciences research (Byrne, 1998). Therefore, we estimated one additional parameter on the theta-delta matrix to account for correlated errors, and the results showed a good fit to the data $\left(\chi^{2}=106.21, p<.01, \mathrm{df}=52, \mathrm{CFI}=.95\right.$, $\mathrm{IFI}=.95$, RMSEA $=.07$; Kline, 2005). A two-factor solution was a better fit to the data than a one-factor solution $\left(\chi^{2}=\right.$ 279.07, $p<.01, \mathrm{df}=53, \mathrm{CFI}=.78, \mathrm{IFI}=.79, \mathrm{RMSEA}=.15 ; \Delta$ $\left.\chi^{2}=172.86, \mathrm{df}=1, p<.05\right)$.

We also conducted a confirmatory factor analysis for the supervisor-reported variables, power distance orientation, and the subordinate's job performance. A two-factor solution (power distance and job performance) was a good fit for the data $\left(\chi^{2}=51.38, p<.05, \mathrm{df}=26, \mathrm{CFI}=.95, \mathrm{IFI}=.95\right.$, RMSEA $=.06)$. A two-factor solution was a better fit to the data than a one-factor solution $\left(\chi^{2}=225.10, p<.01, \mathrm{df}=27\right.$, $\mathrm{CFI}=.60, \mathrm{IFI}=.61, \mathrm{RMSEA}=.16 ; \Delta \chi^{2}=173.72, \mathrm{df}=1, p<$ $.05)$.

Polynomial regression and response surface plotting were used to examine our predictions (Edwards \& Parry, 1993). Specifically, polynomial regression of subordinate power distance orientation and supervisor power distance orientation predicting subordinate strain refers to a model that includes higher powers of subordinate power distance orientation and supervisor power distance orientation beyond their linear terms (Cohen et al., 2010). For Hypothesis 1, we create the following hierarchical regression equation:

$$
\begin{aligned}
Y= & b_{0}+b_{1} P+b_{2} S+\mathrm{b}_{3} P^{2}+\mathrm{b}_{4}(P \times S)+b_{5} S^{2} \\
& +e
\end{aligned}
$$

$P$ represents subordinate power distance orientation, and $S$ represents supervisor power distance orientation. After testing the equations using polynomial regression on subordinate strain, we then proceeded to conduct additional tests to examine the curvatures and slopes along $P=S$, which is referred to as the congruence line, and $P=-S$ is referred to as the incongruence and/or misfit line. The slope of the congruence line is calculated from the coefficients estimated in Eq. 1 by computing the quantity $b_{1}+b_{2}$, and the curvature is calculated by computing the quantity $b_{3}+b_{4}+b_{5}$. The slope and curvature of the surface along the incongruence line may be calculated with estimated coefficients from Eq. 1, specifically $b_{1}-b_{2}$ and $b_{3}-b_{4}+b_{5}$, respectively (Edwards \& Cable, 2009; Lambert et al., 2012).

Hypothesis 1 predicts that the more incongruent a subordinate's and his or her supervisor's levels of power distance orientation are, the higher the subordinate's strain. The first equation in Table 2 (strain) shows the unstandardized coefficients as well as the curvatures and slopes along the congruence and incongruence lines for the polynomial regression. Figure 1 depicts the response surface based on these coefficients. 
Table 2 Supervisor-subordinate power distance orientation congruence effects on subordinate job performance when mediated by subordinate job strain

\begin{tabular}{|c|c|c|c|c|c|c|}
\hline \multirow[b]{2}{*}{ Dyad relationship conflict difference } & \multicolumn{2}{|l|}{ Model 1} & \multicolumn{2}{|l|}{ Model 2} & \multicolumn{2}{|l|}{ Model 3} \\
\hline & $0.185^{*}$ & $(0.086)$ & -0.009 & $(0.053)$ & 0.010 & $(0.054)$ \\
\hline Dyad tenure & -0.028 & $(0.022)$ & 0.005 & $(0.014)$ & 0.002 & $(0.014)$ \\
\hline Supervisor education & 0.040 & $(0.081)$ & -0.029 & $(0.050)$ & -0.025 & $(0.050)$ \\
\hline Supervisor work experience & $-0.014 \dagger$ & $(0.007)$ & 0.003 & $(0.004)$ & 0.002 & $(0.004)$ \\
\hline Supervisor gender ( 1 = female $)$ & -0.097 & $(0.158)$ & $-0.237^{*}$ & $(0.098)$ & $-0.247 *$ & $(0.097)$ \\
\hline Subordinate gender $(1=$ female $)$ & $-0.268 \dagger$ & $(0.153)$ & $0.168 \dagger$ & $(0.095)$ & 0.141 & $(0.094)$ \\
\hline Subordinate age & -0.029 & $(0.052)$ & -0.019 & $(0.032)$ & -0.022 & $(0.032)$ \\
\hline Subordinate race ( 1 = white $)$ & 0.164 & $(0.153)$ & 0.151 & $(0.095)$ & $0.168 \dagger$ & $(0.094)$ \\
\hline Service industry & -0.106 & $(0.144)$ & 0.128 & $(0.089)$ & 0.117 & $(0.089)$ \\
\hline Subordinate power distance $(P)$ & 0.054 & $(0.124)$ & -0.037 & $(0.077)$ & -0.031 & $(0.076)$ \\
\hline Supervisor power distance $(S)$ & 0.106 & $(0.131)$ & $-0.153 \dagger$ & $(0.081)$ & $-0.142 \dagger$ & $(0.080)$ \\
\hline$P^{2}$ & 0.095 & $(0.131)$ & 0.110 & $(0.081)$ & 0.119 & $(0.080)$ \\
\hline$P \times S$ & $-0.798 * *$ & $(0.192)$ & -0.058 & $(0.119)$ & -0.140 & $(0.124)$ \\
\hline $\mathrm{S}^{2}$ & 0.065 & $(0.098)$ & $0.125^{*}$ & $(0.061)$ & $0.132 *$ & $(0.060)$ \\
\hline Strain (subordinate-reported) & & & & & $-0.103 *$ & $(0.049)$ \\
\hline Constant & $2.966 * *$ & $(0.367)$ & $4.167 * *$ & $(0.227)$ & $4.472 * *$ & $(0.267)$ \\
\hline \multirow[t]{2}{*}{$R^{2}$} & 0.179 & & 0.115 & & 0.140 & \\
\hline & Coef. & & & SD & & \\
\hline \multicolumn{7}{|l|}{ Congruence $(S=P)$ line } \\
\hline Slope & & 0.16 & & $(0.16)$ & & \\
\hline Curvature & & $-0.64 * *$ & & $(0.20)$ & & \\
\hline \multicolumn{7}{|l|}{ Congruence $(S=-P)$ line } \\
\hline Slope & & -0.05 & & $(0.20)$ & & \\
\hline Curvature & & $0.96 * *$ & & $(0.25)$ & & \\
\hline
\end{tabular}

$n=172$. The coefficients and standard errors (in parentheses) are reported

$* p<.05$

$* * p<.01$. (two-tailed)

$\dagger p<.10$

Table 2 also shows that the polynomial block resulted in a change in $R^{2}$ beyond control variables $(p<.01)$ and the surface along the incongruence line revealed a U-shape (curvature $=.96, p<.01)$ on strain. Figure 1 reveals that it is
Fig. 1 Supervisor-subordinate power distance congruence effects on subordinate job strain

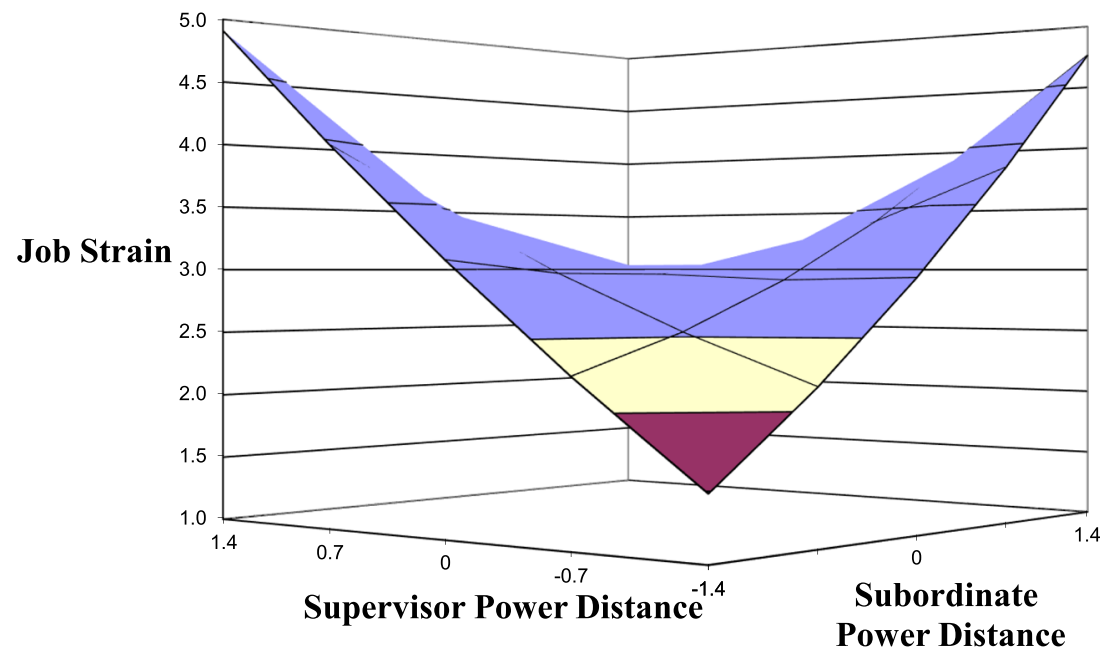


Table 3 Results from tests of indirect effects of power distance orientation incongruence on subordinate job performance

\begin{tabular}{llll}
\hline Variables & $\begin{array}{l}\text { Power distance orientation } \\
\text { (block variable) to strain }\end{array}$ & $\begin{array}{l}\text { Strain to performance controlling } \\
\text { for power distance incongruence }\end{array}$ & $\begin{array}{l}\text { Indirect effect of strain } \\
\text { to performance }\end{array}$ \\
\hline & $\alpha$ path & $\beta$ path & $\alpha \times \beta$ \\
Unstandardized results & $1.00^{* *}$ & $-0.103^{*}$ & $-0.103^{*}$ \\
$\begin{array}{c}\text { 95\% bias-corrected } \\
\text { bootstrapped CI }\end{array}$ & $(.097,1.303)$ & $(-.198,-.008)$ & $(-.191,-.028)$ \\
$\begin{array}{l}\text { Standardized results } \\
\text { 95\% bias-corrected }\end{array}$ & $.425^{* *}$ & $-.098^{*}$ & $-.042^{*}$ \\
$\quad(.298, .553)$ & $(-.184,-.013)$ & $(-.077,-.011)$ \\
\hline
\end{tabular}

Significance of bootstrapped indirect effect was based on 95\% confidence interval (CI) for 1000 bootstrap samples

indeed curved upward along the incongruence line, supporting hypothesis 1 . The incongruence line $(P=-S)$ is from the left corner to the right corner of the figure. Specifically, for levels of subordinate strain on the left side of the plane, supervisor power distance orientation exceeds that of the subordinate, while on the right side of the plane, subordinate power distance orientation exceeds that of the supervisor. In support of the incongruence prediction related to H1, Fig. 1 demonstrates that higher levels of subordinate power distance and lower levels of supervisor power distance (right top corner of Fig. 1), or lower levels of subordinate power distance and higher levels of supervisor power distance (left top corner of Fig. 1), have the highest levels of job strain. Interestingly, although not hypothesized, we found that, on our strain measure, the response surface along the congruence line was also significantly curvilinear in the form of an inverted U-shape (curvature $=-.64, p<.01$ ). This suggests that subordinate strain decreases more sharply as both subordinate and supervisor power distance orientations become lower or higher from some point, in our case, the value 3. Specifically, subordinate strain decreases more rapidly when there is congruence where both supervisor and subordinate have low power distance than vice versa. When the absolute difference between supervisor power distance and subordinate power distance is within 1 (middle part of Fig. 1), employee job strain (average $=2.524$ ) will be lower than otherwise (average $=2.921)($ difference $=-.396, t=2.282, p<0.05)$.

We next investigate whether mediation occurs as predicted in hypothesis 2 . Models 2 and 3 (Table 2) show effects of the polynomial term on subordinate job performance. In model 3 , we added strain to the regression to examine the effect of strain on job performance after accounting for the controls and five polynomial terms. To better understand the nature of the mediation, we first created a block variable by using the estimated standardized beta coefficients for the five polynomial terms reported in model 1 (i.e., block related to strain) (Edwards \& Cable, 2009). We ran our mediation analysis using the block variable instead of the individual components of the polynomial equation (Matta et al., 2015; Zhang et al., 2012). The indirect effect of power distance incongruence on job performance via strain can be computed as a product of the coefficient of the block variable on job strain (the $\alpha$ path) and the coefficient of job strain on performance (the $\beta$ path) (Zhang et al., 2012). We used model 1 in Table 2 to create a block variable after accounting for control variables. We then calculated the " $\alpha$ " and " $\beta$ " paths of the mediation model (see Table 3), through which we calculated the indirect effect of the block variable to job performance. In line with these studies, we used 1000 bootstrapped samples to calculate $95 \%$ confidence intervals. Our analyses depicted in Table 3 reveal that power distance orientation incongruence is associated with our mediator (the " $\alpha$ " path), strain ( $b=1,95 \%$ confidence interval based on 1000 bootstrap samples ranged from .097 to 1.303). The mediator, in turn, decreases the level of job performance in an indirect, or mediated (the " $\beta$ " path), effect ( $b=$ $-.103,95 \%$ confidence interval ranged from -.198 to -.008 ). These analyses suggest the indirect effect of strain to performance is -0.103 (95\% confidence interval ranged from -.191 to -.028), supporting the mediation prediction in $\mathrm{H} 2$. Following Zhang et al. (2012) and Matta et al. (2015), Table 3 also presents standardized results, which provide similar conclusion as that of the unstandardized results. In sum, hypothesis 2 is supported.

\section{Discussion}

Experiencing stressors at work is a key source of employee strain (APA, 2018). The present study tests whether and why supervisor-subordinate incongruence on power distance values reduces subordinate job performance, presenting subordinate strain as a mechanism by which this happens. Despite efforts to study the effects of individual or societal power distance orientation, we understand very little about how supervisors and subordinates with similar (and dissimilar) value orientations, and backgrounds may interact to influence work outcomes (Reus, 2012; Zhang et al., 2012). In the present study, we extended theory and research on power distance orientation and supervisor-subordinate value incongruence by integrating these streams. We found that a subordinate's 
strain mediates the relationship between power distance orientation incongruence and subordinate job performance. This has theoretical implications for research as well as practical implications for organizations and their leadership.

\section{Theoretical Implications}

This study demonstrates the mediating role of strain in the relationship between supervisor-subordinate power distance orientation incongruence and important work outcomes for employees. We argue that strain impedes the organization's ability to benefit from supervisor-subordinate value congruence. The integration of the transactional model (Lazarus \& Folkman, 1984) and supervisor-subordinate power distance orientation incongruence highlights the complexity of the relationship between supervisor-subordinate congruence and work outcomes. Specifically, our study found that supervisor-subordinate power distance orientation incongruence increased strain, which decreased job performance.

This study contributes to the stream of research on role theory (Katz \& Kahn, 1966) by revealing that not only the cultural value orientations but also the (in)congruence on said value orientations held by the two actors in a given role episode have important work outcomes. Previous theoretical and empirical studies have considered the societal (Khatri, 2009) and individual influences (Farh et al., 2007; Kirkman et al., 2009) of power distance on work outcomes. However, these studies did not consider the supervisors' role and thus did not examine how the match between the subordinate and supervisor may influence work outcomes. The results demonstrate that the relationship between the match of supervisor and subordinate and work outcomes is complex, and that the positive and negative consequences vary based on the levels of subordinate and supervisor value orientation congruence.

Moreover, we contribute to research on Lazarus and Folkman's transactional model of stress (1984) by drawing on congruence research and finding that power distance orientation congruence (incongruence) leads to reduced (increased) strain. Our results demonstrate a remarkably symmetric relationship between incongruence (high-low dyads versus low-high dyads) and the increase of a subordinate's strain, suggesting that matching subordinates and supervisors may be beneficial in developing and maintaining a healthy work environment. This is an interesting finding that may contradict earlier work on power distance in the organization (Khatri, 2009) by suggesting that neither high power distance orientation nor low power distance orientation in isolation has an advantage over the other in reducing employee strain. Instead, it is the congruence between key actors in the role episode that ultimately matters. Having congruent values to one's supervisor may result in less depletion of personal resources (Lazarus \& Folkman, 1984), which mitigates strain and allows employees to perform better. A potential extension of our framework could be team power distance congruence, where these congruence effects may play out differently.

\section{Practical Implications}

The study has important implications for reducing stressors in the work environment and facilitating a setting for high job performance. Because employees who are supported by their direct supervisors are generally more committed to their organizations and exhibit better performance (Frear et al., 2018), providing cultural sensitivity training would be beneficial, especially when a firm is in an environment that naturally cultivates high power distance (Lovelace \& Rosen, 1996; House et al., 2002). It is important to recognize that power distance orientation incongruence between supervisor and subordinates can result in negative outcomes; so, organizations can be prepared for situations that arise. This will help organizations and their leaders develop strategies for managing these dyads or giving employees more flexibility to transfer to another department; so, they feel a greater sense of well-being and can perform effectively.

Moreover, employee strain can have bottom line implications for employers, because stressors tend to increase job withdrawal (Lehman \& Simpson, 1992) and reduce effort (Koslowsky, 2009). According to the turnover meta-analysis by Griffeth et al. (2000), stress factors had among the largest (absolute value) overall sample size weighted corrected correlations with turnover $(\rho=.16)$, compared with satisfaction factors $(\rho=.17)$, compensation factors $(\rho=.08)$, leadership factors $(\rho=.17)$, co-worker factors $(\rho=.11)$, and other factors including chances of promotion $(\rho=.11)$. The organizational costs of employee withdrawal in the form of voluntary turnover (Griffeth et al., 2000; Mitra et al., 1992) and the associated losses in productivity (Eder \& Eisenberger, 2008) are estimated to be as much as $\$ 200$ billion annually (Murphy, 1993; this would be over $\$ 360$ billion in 2020 when adjusted for inflation). Although strain is one of many factors that can contribute to these losses, its contribution to workplace disengagement is about as high as satisfaction with work and leadership (Griffeth et al., 2000). Thus, employers may consider whether they have a responsibility to themselves, their employees, and their shareholders to make the workplace reasonably pleasant for employees so that employees can be themselves, feel at ease, and get their work done well. Making a good supervisor-subordinate match with regard to individual values may be the right thing to do for all stakeholders involved.

In practice, however, it may be difficult for employers to ensure a good match between supervisors and subordinates with respect to their values and other deeply held beliefs, for that matter (e.g., political affiliation, religious beliefs) (van Vianen, 2018; Vogel et al., 2016). There are at least two reasons for this. One reason is that, sometimes, the job-related 
skills needed to complete the work on some projects necessitate putting people together who have the right skills and are available to work on the project but who may differ in values. A second reason is that human resource managers and supervisors may be uncomfortable asking employees personal questions that are not directly related to the job itself, even if relevant to better matching (e.g., Cifre et al., 2013). Human resource managers are mindful not to ask sensitive questions that are not job-related unless there is a business need, for fear of invading employees' privacy or creating the impression that such information may be used in a discriminatory manner to favor some over others (van Vianen, 2018). Inevitably, this means that employees bring deep-seated beliefs and values with them to work (i.e., republican or democrat, high power distance or low power distance) and must be able to work with people whose views are directly contradicting theirs. Incongruence of values between subordinates and supervisors may be even more intense when employees feel unable to leave their jobs due to weak labor markets during economic recovery (e.g., after 2008) (Harding \& Mackenzie, 2014), including the high levels of unemployment during the COVID19 pandemic in 2020.

Then, what are human resource managers to do? We offer three suggestions. First, human resource managers should consider emphasizing specific and measurable employee goals, which can be evaluated objectively based on job contributions to avoid the appearance of impropriety, especially among supervisor-subordinate dyads who do not share some important values. Second, having superordinate goals (defined as goals that both parties can agree upon) at the organizational level will help to reduce tensions between parties who would otherwise clash (Sherif et al., 1961). In this case, superordinate goals could be quarterly goals set by the company overall or the division in which the supervisor and subordinate dyad works. Being able to focus on those performance goals for the good of the organization should allow them to put aside their individual value differences and do what is best for the organization. Third, human resource managers could provide mediation and/or offer regular training for groups on conflict resolution and emotional intelligence to help people resolve value conflicts in a diplomatic way once tensions surface. It is especially important to avoid letting disagreements turn into personal/emotional conflicts, because those are the most damaging (De Dreu \& Weingart, 2003), and often the relationships cannot be salvaged when they reach that point. If these value differences are properly managed and even welcomed, we propose that employees will experience less rather than more strain and may instead experience more elaboration of task-relevant information with their supervisors (Van Knippenberg et al., 2004). Although many jobs do not have specific, measurable goals, and employees sometimes learn to game goals that exist, these suggestions present a starting point and a few interventions that organizations may use to avoid the problems associated with supervisor-subordinate value incongruence.

Moreover, the results presented in our figure imply that there are ranges of (in)congruence where levels of employee strain will be low to moderate. When the absolute difference between supervisor power distance and subordinate power distance is within the middle part of Fig. 1, employee job strain (average $=2.524$ ) will be lower than otherwise (average $=2.921)($ difference $=-.396, t=2.282, p<0.05)$. Employees' strain is low when their power distance values are congruent with those of their supervisor, but strain is at least moderate when the amount of incongruence between them is also moderate. This implies that moderate levels of value differences between supervisor and subordinates are manageable.

\section{Limitations and Future Research}

Our study has several limitations. First, the data were collected from working graduate students in the USA. The USA is a low power distance country, where one could naturally expect to see fewer high supervisor power distance orientation-low subordinate power distance orientation dyads. Consequently, this may limit the generalizability of our study, particularly for settings in high power distance orientation societies. Nevertheless, sampling in a low power distance setting could reduce variance in our sample and make it more difficult to detect effects, suggesting that our study represents a conservative test (Zhang et al., 2012). In addition, research comparing country-level differences on the influence of power distance orientation and work outcomes in China and the USA did not find support for country-level effects influencing the individual-level power distance orientation construct (Kirkman et al., 2009; Schaubroeck et al., 2007). Nonetheless, casting a broader net to test the relationship between country- and individual-level power distance may be fruitful for future research, particularly in contexts such as South America and Central and Eastern Europe where other cultural factors may emerge. Along these lines, we acknowledge that the working university students in our US population reflects more of a "white collar" sample and may not be generalizable to a "blue collar" setting. Future research should explore power distance (in)congruence effects among participants not only in a different national culture but also in a blue collar setting.

Second, we sampled a specific time frame to best capture dyads and avoid attrition. This leaves unanswered questions about the sequential effects of dyad value incongruence and dyad changes over time (Boon \& Biron, 2016). For instance, if a person moves from an incongruent supervisor-subordinate dyad relationship to a congruent dyad relationship, do work outcomes and strain change? In addition, our sampling time frame makes it difficult to establish causality. Our study 
design collecting a survey from both subordinates and supervisors is a recommended way to reduce common method variance concerns (Podsakoff et al., 2003). Nonetheless, temporal ordering between the independent and dependent variables would best be established by administering surveys at multiple points in time. Future research could examine causality by following subordinates and supervisors over time.

Third, this study focused on value orientation rather than behavioral manifestation of supervisor and subordinate power distance orientation. To be certain, an individual's power distance orientation may represent a durable behavioral tendency, but we recognize that, while value orientation is a strong proxy for behavior, actual behavior would be a preferred predictor of work outcomes. In particular, we utilized a selfreported measure of power distance orientation. As such, reciprocal reporting may be beneficial where the supervisor rates the subordinate and vice versa (Zhang et al., 2012). Agreement on power distance congruence in the dyad may offer an interesting route for future studies.

Fourth, future research may build upon our findings by examining whether job performance may suffer in high power distance cultures because subordinates do not want to contradict the opinions of their supervisors. Our sample is from the USA, which is relatively low on power distance. Future research may assess how innovative ideas from those lower in the organizational hierarchy can surface in high power distance countries without violating social norms. For example, Daniels and Greguras (2014) suggested that presenting ideas through anonymous forums may be effective in high power distance settings. Also, future research can investigate how human resource practices (e.g., having highlevel managers withhold judgment until their subordinates have presented their ideas, or encouraging friendly competition between subordinate groups for innovative ideas which managers then judge after presentation are delivered) may facilitate job performance in settings where power distance orientation is high (Daniels \& Greguras, 2014). Setting norms that encourage innovation while honoring social norms would be ideal for organizations in high power distance countries.

Fifth, while we measure job performance, we do not measure other more discretionary types of performances like organizational citizenship behavior. Role theory differentiates between prescribed and discretionary roles (Katz \& Kahn, 1966). In this study, we did not measure discretionary role performance. Research shows that there is only a small relationship between task and contextual performance; so, it makes sense to treat them and study them individually (Motowidlo \& Van Scotter, 1994). The organizational justice meta-analysis conducted by Colquitt et al. (2001) found small- to medium-sized positive effects between being treated fairly and organizational citizenship behavior. Therefore, we would predict that the effects of our supervisor-subordinate incongruence dynamics will be the same or stronger when impacting discretionary behavior, because citizenship behavior could be the first action disgruntled employees jettison. However, this is speculation on our part, and future research should empirically test whether the results of this study generalize to discretionary forms of employee behavior.

Finally, we believe a longitudinal design might capture the dynamics mentioned above. Furthermore, it could be certain subordinate attributes that contribute to more power distance congruence. For example, does a supervisor exposed to a department of extraverted employees begin to shift his/her perceptions of power distance orientation over time to one which is lower such that an open door policy is adopted? Such a departmental contextual factor, such as leading a group of 10 to 12 extraverted employees, could influence the nature of power distance orientation congruence at the dyadic level. In sum, it is quite possible that both supervisor and subordinate attributes can influence the other party's power distance orientation over time. The static nature of the present study was not able to account for such influences; therefore, we recommend that future research delve deeper into such possibilities.

\section{Conclusion}

In the current study, we identify the potential intervening role of strain in the relationship between supervisor-subordinate power distance orientation incongruence and subordinate job performance. We suggest that a critical (yet understudied) element of this relationship in predicting strain and job performance is the (in)congruence in values between the subordinate and the supervisor, not just the subordinate or the supervisor values alone. From a practical standpoint, it is not realistic for a supervisor to hire only employees who are congruent with their power distance orientation because, often times, neither the supervisor nor subordinate really knows the other party's values prior to the start of the employment relationship. It is more feasible for an organization to move an employee to a department where there is better fit between him or her and the new supervisor, as this might go a long way in reducing strain, thereby contributing positively to job performance. Our recommendation is that awareness of power distance orientation dynamics is understood from the standpoint of the subordinate, the supervisor, and the company. Such recognition of power distance orientation dynamics can create an environment where employees are supervised by the most appropriate manager and can better contribute to the organization's success. 


\section{References}

Adkins, C. L., \& Russell, C. J. (1997). Supervisor-subordinate work value congruence and subordinate performance: A pilot study. Journal of Business and Psychology, 12, 205-218.

American Institute of Stress. (2018). Workplace stress. http://www.stress. org/workplace-stress

American Psychological Association. (2018). Coping with stress at work. http://www.apa.org/helpcenter/work-stress.aspx

American Psychological Association. (2020). APA Dictionary of Psychology. https://dictionary.apa.org/strain

Beehr, T. A., \& Bhagat, R. S. (1985). Human stress and cognition in organizations: An integrated perspective. John Wiley \& Sons.

Beehr, T. A., Jex, S. M., Stacy, B. A., \& Murray, M. A. (2000). Work stressors and coworker support as predictors of individual strain and job performance. Journal of Organizational Behavior, 21, 391-405.

Bochner, S., \& Hesketh, B. (1994). Power distance, individualism/collectivism, and job-related attitudes in a culturally diverse work group. Journal of Cross-Cultural Psychology, 25(2), 233-257.

Boon, C., \& Biron, M. (2016). Temporal issues in person-organization fit, person-job fit and turnover: The role of leader-member exchange. Human Relations, 69(12), 2177-2200.

Brockner, J., Ackerman, G., Greenberg, J., Gelfand, M. J., Francesco, A. M., Chen, Z. X., Leung, K., Bierbrauer, G., Gomez, C., Kirkman, B. L., \& Shapiro, D. (2001). Culture and procedural justice: The influence of power distance on reactions to voice. Journal of Experimental Social Psychology, 37(4), 300-315.

Byrne, B. M. (1998). Structural equation modeling with LISREL, Prelis, and Simplis: Basic Concepts, Applications, and Programming. Lawrence Erlbaum Associates.

Cable, D. M., \& DeRue, D. S. (2002). The convergent and discriminant validity of subjective fit perceptions. Journal of Applied Psychology, $87,875-884$

Caplan, R. D. (1987). Person-environment fit theory and organizations: Commensurate dimensions, time perspectives, and mechanisms. Journal of Vocational Behavior, 31, 248-267.

Carl, D., Gupta, V., \& Javidan, M. (2004). Power distance. In R. J. House, P. J. Hanges, M. Javidan, P. W. Dorfman, \& V. Gupta (Eds.), Culture, leadership, and organizations: The GLOBE study of 62 cultures (pp. 437-512). Sage Publications.

Centers for Disease Control and Prevention. (2016). Workplace health promotion: Using the workplace to improve the nation's health: At a glance 2016. https://www.cdc.gov/ chronicdisease/resources/publications/aag/workplace-health. htm. Retrieved November 25, 2020.

Centers for Disease Control and Prevention. (2019). https://www.cdc. gove/chronicdisease/about/costs/index.htm ().

Chemers, M. M., Hays, R. B., Rhodewalt, F., \& Wysocki, J. (1985). A person-environment analysis of job stress: A contingency model explanation. Journal of Personality and Social Psychology, 49, 628-635.

Cifre, E., Vera, M., Rodriguez-Sanchez, A. M., \& Pastor, M. C. (2013). Job-person fit and well-being from a gender perspective. Journal of Work and Organizational Psychology, 29, 161-168.

Clarke, N., \& Mahadi, N. (2017). Mutual recognition respect between leaders and followers: Its relationship to follower job performance and well-being. Journal of Business Ethics, 141(1), 163-178.

Clugston, M., Howell, J. P., \& Dorfman, P. W. (2000). Does cultural socialization predict multiple bases and foci of commitment? Journal of Management, 26, 5-30.

Cohen, A., Nahum-Shani, I., \& Doveh, E. (2010). Further insight and additional inference methods for polynomial regression applied to the analysis of congruence. Multivariate Behavioral Research, 45, $828-852$.
Cole, M. S., Carter, M. Z., \& Zhang, Z. (2013). Leader-team congruence in power distance values and team effectiveness: The mediating role of procedural justice climate. Journal of Applied Psychology, 98(6), 962-973.

Colquitt, J. A., Conlon, D. E., Wesson, M. J., Porter, C. O. L. H., \& Ng, K. Y. (2001). Justice at the millennium: A meta-analytic review of 25 years of organizational justice research. Journal of Applied Psychology, 86, 425-445.

Cook, D. (2017). Workplace stress costing employers $\$ 500$ billion annually. benefitsPRO. https://www.benefitspro.com/2017/10/20/ workplace-stress-costing-employers-500-billion-ann/ (retrieved November 25, 2020).

Daniels, M. A., \& Greguras, G. J. (2014). Exploring the nature of power distance implications for micro-and macro-Level theories, processes, and outcomes. Journal of Management, 40(5), 1202-1229. https://doi.org/10.1177/0149206314527131.

De Dreu, C. K. W., \& Weingart, L. R. (2003). Task versus relationship conflict, team effectiveness, and team member satisfaction: A metaanalysis. Journal of Applied Psychology, 88, 741-749.

Dorfman, P. W., \& Howell, J. P. (1988). Dimensions of national culture and effective leadership patterns. Advances in International Cooperative Management, 3, 137-150.

Eder, P., \& Eisenberger, R. (2008). Perceived organizational support: Reducing the negative influence of coworker withdrawal behavior. Journal of Management, 34, 55-68.

Edwards, J. R., \& Cable, D. M. (2009). The value of congruence. Journal of Applied Psychology, 94, 654-677.

Edwards, J. R., \& Parry, M. E. (1993). On the use of polynomial regression equations as an alternative to difference scores in organizational research. Academy of Management Journal, 36, 1577-1613.

Edwards, J. R., \& Shipp, A. J. (2007). The relationship between personenvironment fit and outcomes: An integrative theoretical framework. In C. Ostroff \& T. A. Judge (Eds.), Perspectives on organizational fit (pp. 209-258). Lawrence Erlbaum.

Edwards, J. R., \& Van Harrison, R. (1993). Job demands and worker health: Three-dimensional reexamination of the relationship between person-environment fit and strain. Journal of Applied Psychology, 78, 628-648.

Edwards, J. R., Caplan, R. D., \& Van Harrison, R. (1998). Personenvironment fit theory: Conceptual foundations, empirical evidence, and directions for future research. In C. L. Cooper (Ed.), Theories of organizational stress (pp. 28-67). Oxford University Press.

Edwards, J. R., Cable, D. M., Williamson, I. O., Lambert, L. S., \& Shipp, A. J. (2006). The phenomenology of fit: Linking the person and environment to the subjective experience of person-environment fit. Journal of Applied Psychology, 91, 802-827.

Erdogan, B., Kraimer, M. L., \& Liden, R. C. (2004). Work value congruence and intrinsic career success: the compensatory roles of leadermember exchange and perceived organizational support. Personnel Psychology, 57(2), 305-332.

Erez, M. (1994). Towards a model of cross-cultural I/O psychology. Handbook of industrial and organizational psychology, 4, 569-607.

Erez, M. (2010). Culture and job design. Journal of Organizational Behavior, 31, 389-400.

Farh, J. L., Dobbins, G. H., \& Cheng, B. S. (1991). Cultural relativity in action: A comparison of self-rating made by Chinese and U.S. workers. Personnel Psychology, 44, 129-147.

Farh, J. L., Hackett, R. D., \& Liang, J. (2007). Individual-level cultural values as moderators of perceived organizational support-employee outcomes relationships in China: Comparing the effects of power distance and traditionality. Academy of Management Journal, 50(3), 715-729.

Folkman, S., \& Lazarus, R. S. (1985). If it changes it must be a process: Study of emotion and coping during three stages of a college examination. Journal of Personality and Social Psychology, 48, 150-170. 
Folkman, S., \& Lazarus, R. S. (1990). Coping and emotion. In N. L. Stein, B. Leventhal, \& T. Trabasso (Eds.), Psychological and biological approaches to emotion (pp. 313-332). Lawrence Erlbaum Associates.

Frear, K. A., Donsbach, J., Theilgard, N., \& Shanock, L. R. (2018). Supported supervisors are more supportive, but why? A multilevel study of mechanisms and outcomes. Journal of Business and Psychology, 33(1), 55-69.

French, J. R., Caplan, R. D., \& Harrison, R. V. (1982). The mechanisms of job stress and strain. Wiley.

Gelfand, M. J., Bhawuk, D. P., Nishii, L., \& Bechtold, D. (2004). Individualism and collectivism. In R. J. House, P. J. Hanges, M. Javidan, P. W. Dorfman, \& V. Gupta (Eds.), Culture, leadership, and organizations: The GLOBE study of 62 cultures (pp. 437-512). Sage Publications.

Gelfand, M. J., Erez, M., \& Aycan, Z. (2007). Cross-cultural organizational behavior. Annual Review of Psychology, 58, 479-514.

Griffeth, R. W., Hom, P. W., \& Gaertner, S. (2000). A meta-analysis of antecedents and correlates of employee turnover: Update, moderator tests, and research implications for the next millennium. Journal of Management, 26, 463-488.

Harding, R., \& Mackenzie, M. (2014). US jobs data puncture recovery hopes. Financial Times, https://www.ft.com/content/e9a9f98079fc-11e3-a3e6-00144feabdc0, Accessed Dec. 6, 2020.

Hofstede, G. (2001). Culture's consequences: Comparing values, behaviors, institutions and organizations across nations. Sage.

House, R., Javidan, M., Hanges, P., \& Dorfman, P. (2002). Understanding the cultures and implicit leadership theories across the globe: An introduction to project GLOBE. Journal of World Business, 37, 3-10.

Hu, L., \& Bentler, P. M. (1999). Cutoff criteria for fit indexes in covariance structure analysis: Conventional criteria versus new alternatives. Structural Equation Modeling, 6, 1-55.

Hunter, L. W., \& Thatcher, S. M. B. (2007). Feeling the heat: Effects of stress, commitment, and job experience on job performance. Academy of Management Journal, 50, 953-968.

Imai, L., \& Gelfand, M. J. (2010). The culturally intelligent negotiator: The impact of cultural intelligence (CQ) on negotiation sequences and outcomes. Organizational Behavior and Human Decision Processes, 112, 83-89.

Jackson, S. (1983). Participation in decision making as a strategy for reducing job-related strain. Journal of Applied Psychology, 68(1), 3-19.

Javidan, M., House, R. J., Dorfman, P. W., Hanges, P. J., \& De Luque, M. S. (2006). Conceptualizing and measuring cultures and their consequences: A comparative review of GLOBE's and Hofstede's approaches. Journal of International Business Studies, 37(6), 897914.

Jehn, K. A. (1995). A multimethod examination of the benefits and detriments of intragroup conflict. Administrative Science Quarterly, 40, 256-282.

Jun, S., \& Gentry, J. W. (2005). An exploratory investigation of the relative importance of cultural similarity and personal fit in the selection and performance of expatriates. Journal of World Business, $40,1-8$.

Katz, D., \& Kahn, R. L. (1966). The psychology of organizations. Wiley.

Khatri, N. (2009). Consequences of power distance orientation in organisations. Vision, 13, 1-9.

Kirkman, B. L., Lowe, K. B., \& Gibson, C. B. (2006). A quarter century of culture's consequences: A review of empirical research incorporating Hofstede's cultural value framework. Journal of International Business Studies, 37, 285-320.

Kirkman, B. L., Chen, G., Farh, J.-L., Chen, Z. X., \& Lowe, K. B. (2009). Individual power distance orientation and followers reactions to transformational leaders: A cross-level, cross-cultural examination. Academy of Management Journal, 52, 744-754.
Kline, R. (2005). Principles and practice of structural equation modeling (2nd ed.). The Guilford Press.

Koslowsky, M. (2009). A multi-level model of withdrawal: Integrating and synthesizing theory and findings. Human Resource Management Review, 19, 283-303.

Krishnan, V. R. (2002). Transformational leadership and value system congruence. International Journal of Value-Based Management, $15,19-33$.

Kristof-Brown, A. L., Zimmerman, R. D., \& Johnson, E. C. (2005). Consequences of individual's fit at work: A meta-analysis of person-job, person-organization, person-group, and person-supervisor fit. Personnel Psychology, 58(2), 281-342.

Lambert, L., Tepper, B. J., Carr, J. C., Holt, D. T., \& Barelka, A. J. (2012). Forgotten but not gone: An examination of fit between leader consideration and initiating structure needed and received. Journal of Applied Psychology, 97(5), 913-930.

Lang, J., Thomas, J. L., Bliese, P. D., \& Adler, A. B. (2007). Job demands and job performance: the mediating effects of psychological and physical strain and the moderating effect of role clarity. Journal of Occupational Health Psychology, 12(2), 116-124.

Lazarus, R. S. (1966). Psychological Stress and the Coping Process. McGraw Hill.

Lazarus, R. S., \& Folkman, S. (1984). Stress, Appraisal, and Coping. Springer.

Lee, Y.-T., \& Antonakis, J. (2014). When preference is not satisfied but the Individual is: How power distance moderates person-job fit. Journal of Management, 40(3), 641-675.

Lehman, W. E. K., \& Simpson, D. D. (1992). Employee substance abuse and on-the-job behaviors. Journal of Applied Psychology, 77, 309 321.

LePine, J. A., Podsakoff, N. P., \& LePine, M. A. (2005). A meta-analytic test of the challenge stressor-hindrance stressor framework: An explanation for inconsistent relationships among stressors and performance. Academy of Management Journal, 48, 764-775.

Liao, H., Joshi, A., \& Chuang, A. (2004). Sticking out like a sore thumb: Employee dissimilarity and deviance at work. Personnel Psychology, 57, 969-1000.

Loi, R., Lam, L., \& Chan, K. (2012). Coping with job insecurity: The role of procedural justice, ethical leadership and power distance orientation. Journal of Business Ethics, 108(3), 361-372. https://doi.org/ 10.1007/s10551-011-1095-3.

Lovelace, K., \& Rosen, B. (1996). Differences in achieving personorganization fit among diverse groups of managers. Journal of Management, 22, 703-722.

Matta, F. K., Scott, B. A., Koopman, J., \& Conlon, D. E. (2015). Does seeing "eye to eye" affect work engagement and organizational citizenship behavior? A role theory perspective on LMX agreement. Academy of Management Journal, 58(6), 1686-1708.

Meglino, B. M., Ravlin, E. C., \& Adkins, C. L. (1989). A work values approach to corporate culture: A field test of the value congruence process and its relationship to individual outcomes. Journal of Applied Psychology, 74, 424-432.

Mental Health America. (2017). Mind the Workplace. https://www. mhanational.org/sites/default/files/Mind\%20the\%20Workplace\% 20-\%20MHA\%20Workplace\%20Health\%20Survey\%202017\% 20FINAL.pdf (retrieved November 25, 2020).

Mitra, A., Jenkins, G. D., \& Gupta, N. (1992). A meta-analytic review of the relationship between absence and turnover. Journal of Applied Psychology, 77, 879-889.

Motowidlo, S. J., \& Van Scotter, J. R. (1994). Evidence that task performance should be distinguished from contextual performance. Journal of Applied Psychology, 79, 475-480.

Murphy, K. R. (1993). Honesty in the workplace. Belmont, CA: Brooks/Cole. 
Ostroff, C., Shin, Y., \& Kinicki, A. J. (2005). Multiple perspectives of congruence: relationships between value congruence and employee attitudes. Journal of Organizational Behavior, 26, 591-623.

Perrewé, P. L., \& Zellars, K. L. (1999). An examination of attributions and emotions in the transactional approach to the organizational stress process. Journal of Organizational Rehavior, 20, 739-775.

Pfeffer, J. (2020). Solving the workplace health crisis. IHRIM. https:// www.ihrim.org/2020/06/solving-the-workplace-health-crisis/ (retrieved November 25, 2020).

Podsakoff, P. M., MacKenzie, S. B., Lee, J. Y., \& Podsakoff, N. P. (2003). Common method biases in behavioral research: A critical review of the literature and recommended remedies. Journal of Applied Psychology, 88, 879-903.

Posner, B. B. (2010). Another look at the impact of personal and organizational values congruency. Journal of Business Ethics, 97(4), 535-541.

Rahimnia, F. R., \& Sharifirad, M. (2015). Authentic leadership and employee well-being: The mediating role of attachment insecurity. Journal of Business Ethics, 132(2), 363-377.

Reus, T. H. (2012). Culture's consequences for emotional attending during cross-border acquisition implementation. Journal of World Business, 47, 342-351.

Rosenthal, R., \& Rosnow, R. L. (2008). Essentials of behavioral research: Methods and data analysis (3rd ed.). Boston: McGraw-Hill.

Saks, A. M., \& Ashforth, B. E. (1997). A longitudinal investigation of the relationships between job information sources, application perceptions of fit, and work outcomes. Personnel Psychology, 50, 395-426.

Schaubroeck, J., Cha, S. E., \& Lam, S. S. K. (2007). Embracing transformational leadership: Team values and the impact of leader behavior on team performance. Journal of Applied Psychology, 92, 1020-1030.

Seggewiss, B. J., Boeggemann, L. M., Straatmann, T., Mueller, K., \& Hattrup, K. (2019). Do values and value congruence both predict commitment? A refined multi-target, multi-value investigation into a challenged belief. Journal of Business and Psychology, 34(2), 169-187.

Sherif, M., Harvey, O. J., White, B. J., Hood, W. R., \& Sherif, C. W. (1961). Intergroup Conflict and Cooperation: The Robbers' Cave Experiment. University of Oklahoma Press.

Singelis, T. M., Triandis, H. C., Bhawuk, D. P. S., \& Gelfand, M. J. (1995). Horizontal and vertical dimensions of individualism and collectivism: A theoretical and measurement refinement. CrossCultural Research, 29, 240-275.

Skiba, T., \& Wildman, J. L. (2019). Uncertainty reducer, exchange deepener, or self-determination enhancer? Feeling trust versus feeling trusted in supervisor-subordinate relationships. Journal of Business and Psychology, 34(2), 219-235.
Taras, V., Steel, P., \& Kirkman, B. L. (2012). Improving national cultural indices using a longitudinal meta-analysis of Hofstede's dimensions. Journal of World Business, 47, 329-341.

Tepper, B. J., \& Taylor, E. C. (2003). Relationships among supervisors' and subordinates' procedural justice perceptions and organizational citizenship behaviors. Academy of Management Journal, 45, 97-105.

Tillman, J., Hood, A., \& Richard, O. C. (2017). Supervisor-subordinate relationship conflict asymmetry and subordinate turnover intentions: The mediating roles of stress and counterproductive work behaviors. Journal of Behavioral and Applied Management, 17(3), 169-196.

Triandis, H. C., Kurowski, L. L., \& Gelfand, M. J. (1994). Workplace diversity. In H. C. Triandis, M. D. Dunnette, \& L. M. Hough (Eds.), Handbook of industrial and organizational psychology (pp. 769827). Consulting Psychologists Press.

Turban, D. B., \& Jones, A. P. (1988). Supervisor-subordinate similarity: Types, effects, and mechanisms. Journal of Applied Psychology, 73, 228-262.

Tyler, T. R., Lind, E. A., \& Huo, Y. J. (2000). Cultural values and authority relations: The psychology of conflict resolution across cultures. Psychology, Public Policy, and Law, 6, 1138-1163.

Van Knippenberg, D., De Dreu, C. K., \& Homan, A. C. (2004). Work group diversity and group performance: an integrative model and research agenda. Journal of Applied Psychology, 89(6), 1008-1022.

Van Vianen, A. E. M. (2000). Person-organization fit: The match between newcomers' and recruiters' preferences for organizational cultures. Personnel Psychology, 53, 113-149.

van Vianen, A. E. M. (2018). Person-environment fit: A review of its basic tenets. Annual Review of Organizational Psychology and Organizational Behavior, 5, 75-101.

Vogel, R. M., Rodell, J. B., \& Lynch, J. W. (2016). Engaged and productive misfits: How job crafting and leisure activity mitigate the negative effects of value incongruence. Academy of Management Journal, 59(5), 1561-1584.

Wexley, K. N., Alexander, R. A., Greenawalt, J. P., \& Couch, M. A. (1980). Attitudinal congruence and similarity as related to interpersonal evaluations in manager-subordinate dyads. Academy of Management Journal, 23, 320-330.

Zhang, Z., Wang, M., \& Shi, J. (2012). Leader-follower congruence in proactive personality and work outcomes: The mediating role of leader-member exchange. Academy of Management Journal, 55(1), 111-130.

Publisher's Note Springer Nature remains neutral with regard to jurisdictional claims in published maps and institutional affiliations. 